\title{
1. Methodologies to study human rights law as an integrated whole from a users' perspective: lessons learnt
}

\section{Ellen Desmet}

\section{INTRODUCTION}

This chapter reflects on methodological approaches to study human rights law as an integrated whole from a users' perspective. ${ }^{1}$ Methodology is one of the criteria for assessing the quality of scientific research. An adequate methodology requires, among other things, being transparent and reflective about choices made, for instance regarding data collection and analysis. There are no clear-cut or definitive answers to methodological questions. As Banakar and Travers have noted: '[W] hat counts is being able to justify a particular decision in relation to your research question, while demonstrating an understanding of how other researchers have encountered similar problems'. ${ }^{2}$

In classical legal research, the explicit attention paid to methodological issues has traditionally been limited. Also in human rights research, a tendency has been observed among both legal scholars and social scientists 'not to spell out their research methods in any details in their publications', whereby 'if the method employed is not carefully explained, the validity of the outcome of a research project cannot be

1 These methodologies were developed in the framework of the IAP project 'The Global Challenge of Human Rights Integration: Towards a Users' Perspective', www.hrintegration.be. The author warmly thanks all members of the Human Rights Integration network for the collaboration and exchanges, as well as the editors for their valuable comments and suggestions.

2 Reza Banakar and Max Travers (eds), Theory and Method in Socio-Legal Research (Oxford, Hart, 2005), 21. 
judged' ${ }^{3}$ During the last decade, however, legal scholars have increasingly engaged with methodology. ${ }^{4}$ Also within human rights research, attention for methodological questions has been growing. ${ }^{5}$

Within the research project 'The Global Challenge of Human Rights Integration: Towards a Users' Perspective', methodology took up a central position from the outset. To dedicate a chapter exclusively to methodology is challenging though, as substantive and methodological issues are inextricably intertwined. On the one hand, the methodology chosen should be adequate to be able to answer the research questions, and thus logically 'flow' from these questions. On the other, methodological choices will inevitably influence the nature of the research findings. It is thus difficult or even impossible to separate methodological issues from conceptual and theoretical matters. With this caveat in mind, this chapter examines the methodological approaches developed to study human rights law as an integrated whole from a users' perspective and highlights innovative contributions that may be useful in other research contexts.

Within the research objective of 'studying human rights law as an integrated whole from a users' perspective', the aspects of 'an integrated approach to human rights law' and 'a users' perspective' are closely related: the multi-layered structure of human rights law and the lack of coordination between various layers become especially apparent from the perspective of the users of human rights law. In specific research, both dimensions do not necessarily have to carry a similar weight though. Research can focus more or exclusively on an integrated approach to

3 Fons Coomans, Fred Grünfeld and Menno T Kamminga, Methods of Human Rights Research (Cambridge, Intersentia, 2009), 13.

4 See eg, Robert Cryer and others, Research Methodologies in EU and International Law (Oxford, Hart, 2011); Hervé Tijssen, 'De juridische dissertatie onder de loep. De verantwoording van methodologische keuzes in juridische dissertaties' (PhD thesis, Tilburg University 2009); Mark Van Hoecke (ed), Methodologies of Legal Research. Which Kind of Method for What Kind of Discipline? (Oxford, Hart, 2011).

5 See eg, Coomans, Grünfeld and Kamminga (n 3); Todd Landman, Studying Human Rights (Abingdon, Routledge, 2006); Bård A Andreassen, Hans-Otto Sano and Siobhán McInerney-Lankford (eds), Research Methods in Human Rights. A Handbook (Cheltenham, Edward Elgar Publishing, 2017). 
human rights law ${ }^{6}$ or predominantly adopt the perspective of one or more users of human rights law. ${ }^{7}$

The chapter first discusses methodological innovation in studying human rights law integration and fragmentation, and then points to methodological refinements in the study of users' perspectives. It continues to identify three emerging characteristics that seem to be shared by many research projects that aim to study human rights integration from a users' perspective. Finally, the relevance beyond the field of human rights law of an integrated approach and a users' perspective are argued and illustrated.

\section{METHODOLOGICAL INNOVATION IN STUDYING HUMAN RIGHTS INTEGRATION AND FRAGMENTATION}

Brems has suggested that an integrated approach to human rights law consists of two dimensions: (i) 'a comprehensive approach to the sources of human rights law', thus including all human rights norms that are relevant in a particular case; and (ii) 'a maximum inclusion of rights holders', thus considering the human rights of all persons affected by a certain situation. ${ }^{8}$ This section presents some possible methodological routes to study these two dimensions of human rights integration. ${ }^{9}$

\subsection{Methodologies to Study Human Rights Norms in an Integrated Way}

In order to engage with human rights norms in an integrated way as well as to reflect on the desirability of maintaining some fragmentation, three specific methodologies have been developed: (i) relational and inclusive case law analysis; (ii) rewriting decisions from a human rights integration

6 See eg, Eva Brems and Ellen Desmet (eds), 'Human Rights Integration: Theorizing the Multilayered Nature of Human Rights Law' (2014) 2-3 European Journal of Human Rights.

7 See eg, Eva Brems and Ellen Desmet (eds), 'Studying Human Rights Law from the Perspective(s) of its Users' (2014) 8(2) HR\&ILD.

8 Eva Brems, 'Should Pluriform Human Rights Become One? Exploring the Benefits of Human Rights Integration' (2014) 3 European Journal of Human Rights 447, 452.

9 The normative argument in favour for (smart) human rights integration is made in ibid and the contribution of Brems in this volume. 
perspective; and (iii) analysing interactions between various branches of human rights law.

\subsubsection{Relational and inclusive case law analysis}

Valeska David developed an 'integrated, relational and inclusive approach' to analyse both norms and rights holders from an integrated perspective. ${ }^{10}$ As norms are concerned, this entails a two-pronged approach. First, David suggests looking beyond the 'obvious' harms and rights when identifying the relevant human rights norms at stake, in order to unveil which other harms and rights are at stake that remain obscured by the dominant narrative of the case. For instance, in a case where the claim concerns an alleged lack of respect for cultural identity, she also investigates whether issues of socio-economic exclusion are at play. This approach is inspired by the analytical tool of intersectionality, as developed in feminist studies. Valeska David operationalizes it as 'crossthinking' 11 or 'asking the other question'. ${ }^{12}$ In addition, David promotes what she calls 'pluralism awareness'. Starting from the observation that human rights norms are embedded in a larger normative environment, she goes beyond an integrated approach to human rights norms, proposing to take into account all relevant state and non-state regulations. ${ }^{13}$ This 'pluralism awareness' builds on the analytical tool of 'relationality' in feminist studies, which focuses on the interconnections between social entities, such as norms. David applies this approach to analyse how the European Court of Human Rights (ECtHR) and the Inter-American Court of Human Rights deal with claims of cultural and economic difference. Such an integrated, relational and inclusive case law analysis does more justice to the multidimensionality of reality, and avoids that cases presenting various human rights problems are reduced to only one aspect.

10 Valeska David, 'Crossing Divides and Seeing the Whole: An Integrated View of Cultural Difference and Economic Disadvantage in Regional Human Rights Courts' (PhD thesis, Ghent University 2018), 31. For the application of this approach to the study of rights holders, see section 1.2.1.

11 See also section 3.1.

12 Inspired by the approach of Matsuda. Mari Matsuda, 'Beside My Sister, Facing the Enemy: Legal Theory Out of Coalition' (1991) 43 SLR 1183, 1189.

13 The attention for non-state normative orders seems inspired by the insights of legal pluralism (see also section 3.1). 


\subsubsection{Rewriting decisions from an integrated perspective on human rights norms}

A second methodological approach to engage with human rights norms in an integrated way concerns rewriting decisions and judgments from a human rights integration perspective ('the rewriting methodology'). In the words of Eva Brems, this means redrafting these decisions " "as if human rights were really one", borrowing or taking inspiration from developments and interpretations throughout the whole multi-layered human rights protection system.' 14

The methodology of rewriting judgments is not new as it has already been applied in for instance feminist research and more recently also in human rights research. ${ }^{15}$ The innovation here consisted in how the rewriting exercise was undertaken, namely from an integrated perspective on human rights law. In a 2017 edited volume, this methodology was applied to decisions of supranational judicial and quasi-judicial human rights monitoring bodies. ${ }^{16}$ These decisions were rewritten by the authors, in order to explore the diversity of ways in which an integrated perspective on human rights could appear at the regional and international level, without necessarily adopting a common theoretical or methodological framework.

The concept of human rights integration was operationalized as borrowing 'good ideas developed in one sphere or layer of human rights law and applying them in another sphere of human rights law' ${ }^{17}$ Five types of borrowing were by way of illustration identified at the outset:

a) from a specific context (group-specific treaty or thematic treaty) to a general context and vice versa; b) from a regional context to the universal context and vice versa; c) intersectionality (integrating different types of group-specific rights); d) indivisibility (integrating economic and social

14 Eva Brems, 'Rewriting Decisions from a Perspective of Human Rights Integration' in Eva Brems and Ellen Desmet (eds), Integrated Human Rights in Practice. Rewriting Human Rights Decisions (Cheltenham, Edward Elgar Publishing, 2017) 2.

15 See Eva Brems (ed), Diversity and European Human Rights. Rewriting Judgments of the ECHR (Cambridge, Cambridge University Press, 2012).

16 Eva Brems and Ellen Desmet (eds), Integrated Human Rights in Practice. Rewriting Human Rights Decisions (Cheltenham, Edward Elgar Publishing, 2017).

17 Brems (n 14) 12. 
rights with civil and political rights); e) borrowing from other, thematically related, fields of international law, such as international criminal law or international development law. ${ }^{18}$

The ideas were not necessarily transposed in an unchanged manner, but could be adapted to the particularities of the human rights regime, actor, case and/or context. The advantage of a rewriting approach is that it invites academics 'to reflect on the issue of human rights integration in a very concrete manner' and to translate this idea into judicial practice. ${ }^{19}$ In this sense, concrete illustrations are provided of types of external sources to include, the way to do so, and the justifications underlying a decision to either integrate or rather maintain some normative divergence. ${ }^{20}$

Future research could usefully apply the rewriting methodology to the national level. At least two differences with rewriting international and regional human rights decisions can be identified. First, the framing of alleged violations at the supranational level is often influenced by the mandate of the forum to which an application is submitted. For instance, in a case concerning discrimination of a woman of colour a claim before the UN Committee on the Elimination of Racial Discrimination would emphasize the racial dimension, whereas an application submitted to the UN Committee on the Elimination of Discrimination against Women would mainly stress the different treatment between men and women. ${ }^{21}$ The absence of thematic division of roles in human rights adjudication at the national level may facilitate an integrated approach to human rights. On the other hand, additional challenges would rise in relation to the direct effect of supranational human rights provisions.

\subsubsection{Analysing interactions between branches of human rights law}

A third methodological approach to reflect upon the current and desirable level of integration of human rights law consists in analysing interactions between branches of human rights law ('the interactions methodology'). In this approach, one subfield or branch of human rights law is focused on ('the focal branch'), in order to analyse its present and possible future

\footnotetext{
18 Ibid.

19 Ibid, 11.

20 Ibid.

21 On forum shopping between human rights bodies at the international and regional level, see Rhona Smith, 'Yilmaz-Dogan $v$ The Netherlands (CERD): forum shopping and intersecting grounds of discrimination thirty years later' in Eva Brems and Ellen Desmet (eds), Integrated Human Rights in Practice. Rewriting Human Rights Decisions (Cheltenham, Edward Elgar Publishing, 2017).
} 
interactions with other branches and with general human rights law. The focal branch may be related to a particular theme (such as torture or racial discrimination) or a certain category of rights holders for whom a tailored regime of rights protection was developed (such as women, children, persons with disabilities, indigenous peoples, minorities or labour migrants).

The development of this methodology was triggered by the observation that different branches of human rights law tend to develop quite separately from one another. This is in a way not surprising, as distinct monitoring bodies have usually been established to follow up on different human rights instruments. Notwithstanding the benefits of specialization and focus, it is suggested that effective human rights protection would be served by reflecting more explicitly and carefully upon the benefits and drawbacks of increased interaction between various subfields of human rights law. ${ }^{22}$ Within the interactions methodology, the concept of integration' is conceived as 'a deliberate effort from one branch of international human rights law to incorporate concepts, methods or practices that originate from another branch of international human rights law' ${ }^{23}$ At the opposite side of the spectrum stands 'isolation', understood as 'a (deliberate or not) disregard of what is going on in other branches of international human rights law' ${ }^{24}$ The in-between position is coined as 'inspiration', referring to 'cases in which direct incorporation of concepts or practices from another branch of international human rights law is not considered appropriate, but where some ideas or dynamics in one branch have nevertheless influenced or could influence ideas or dynamics in another branch'. ${ }^{25}$

This methodology was operationalized using a three-step approach, and for the first time successfully applied to children's rights law as a focal branch. ${ }^{26}$ In a first step, the principles, concepts, techniques and practices that are generally considered as distinctive or unique to the

22 See also the contribution of Brems in this volume.

23 See Eva Brems, Ellen Desmet and Wouter Vandenhole, 'Children's Rights Law and Human Rights Law: Analysing Present and Possible Future Interactions' in Eva Brems, Ellen Desmet and Wouter Vandenhole (eds), Children's Rights Law in the Global Human Rights Landscape: Isolation, Inspiration, Integration (Abingdon, Routledge, 2017) 1.

24 Ibid, 2.

25 Ibid, 1.

26 See Eva Brems, Ellen Desmet and Wouter Vandenhole (eds), Children's Rights Law in the Global Human Rights Landscape: Isolation, Inspiration, Integration (Abingdon, Routledge, 2017). 
focal branch were identified. It was then analysed whether these allegedly distinctive characteristics could be upheld upon closer examination, and, in the affirmative, whether general human rights law and/or other branches of human rights law have learnt or should learn something from these distinctive elements. For children's rights law, for example, these distinctive characteristics included the use of general principles, the notion of best interests of the child, and the inclusion of third parties in the treaty framework. In a second step, the opposite point of departure is taken: neighbouring branches of human rights law are examined so as to identify their distinctive characteristics, and to explore whether and what the focal branch could learn from experiences in other subfields. With respect to children's rights law, the human rights regimes on women, persons with disabilities, indigenous peoples and older persons were scrutinized to that end. In a third and final step, the actual and possible interactions between the focal branch and general human rights law were investigated in specific thematic areas. The analysis consisted of examining whether the relationship between the focal branch and general human rights law in the thematic area could be characterized as one of 'isolation', 'inspiration' or 'integration', and whether the focal branch and human rights law should develop separately, inspire one another, or be further integrated. Concretely, the interplay between children's rights law and human rights law was examined in the context of the following topics: intra-family relations, LGBTQI marginalization, migration, media, the environment, and transnational human rights obligations. The interactions methodology can thus be described as both systemic and systematic: it considers (sub)fields of law as a whole (systemic) and it implies an orderly, three-step approach to study the interactions between these fields (systematic).

\subsubsection{Comparing the three methodologies}

The three methodologies discussed above offer concrete ways to approach human rights norms in an integrated way. They present similarities as well as differences, which may influence the choice between these approaches. Both the rewriting and interactions methodologies operationalize the adoption of an integrated approach to human rights norms as a way of 'borrowing' ideas or concepts from one sphere of human rights law and applying them in another field. Whereas both approaches allow for adaptation and tailoring, this is more explicit in the interactions methodology, which introduced the distinction between 'inspiration' as referring to 'light or indirect forms of influence', and 'integration' as indicating 'more far-reaching and/or more direct forms of 
influence'. ${ }^{27}$ In the rewriting methodology, both forms of influence are considered together under the umbrella term of 'integration'.

All three methodological approaches incorporate a normative perspective: the way they are applied indicates a normative position on whether certain subfields of human rights law should interact more or not. Whereas this normative dimension is explicit in the interactions methodology, it is more implicit in relational and inclusive case law analysis and rewriting decisions, where it is indirectly reflected in decisions to refer to certain ideas or concepts from another field of human rights law when analysing a case or rewriting a decision.

As the scope of the integrated perspective is concerned, both the rewriting and interactions methodologies are in principle limited to human rights law. 28 By contrast, relational and inclusive case law analysis explicitly takes into account all relevant norms, regardless of their source (eg, human rights, state legal orders, non-state normative orders).

Finally, both relational and inclusive case law analysis as well as the rewriting methodology focus in the first instance on a specific human rights decision. The object of analysis is different in the interactions methodology, which takes a particular subfield of human rights law as point of departure. The three methodologies can thus be situated on a continuum ranging from the particular (relational and inclusive case law analysis/rewriting methodology) to the more systemic (interactions methodology).

\subsection{Methodologies to Adopt an Inclusive Perspective on Rights Holders}

A second dimension of human rights integration is to adopt an inclusive perspective on rights holders. To this end, two methodological approaches have been put forward. The relational and inclusive case law analysis proposed by Valeska David to adopt an integrated approach to human rights norms, ${ }^{29}$ also facilitates an inclusive perspective on rights holders. In addition, a case-based approach to human rights violations has been suggested.

27 'In this sense, "integration" may come down in certain cases to an "uncritical embrace", whereas inspiration may suggest a more critical, deliberated and possibly selective interaction.' Brems, Desmet and Vandenhole (n 23) 2.

28 Even though they hold potential for application beyond the field of human rights law, see section 4 .

29 See section 1.1.1. 


\subsubsection{Relational and inclusive case law analysis}

According to Valeska David, adopting an integrated, relational and inclusive approach to the study of rights holders implies a three-step approach. ${ }^{30}$ The first step consists in not only considering the applicants of a case, but also 'other persons potentially affected by the issue'. ${ }^{31}$ This step is grounded in the intrinsic interconnectedness between human beings (relationality). The second step concerns appreciating the various identities of the rights holders involved, building on the insights of intersectionality. Finally, David adopts the tools of intersectionality and relationality to arrive at a more nuanced analysis of the agency of rights holders, as she finds that judicial decisions tend to portray rights holders as either completely autonomous (and thus responsible for their human rights problems, such as poverty) or fully dependent (and thus in need of protection, such as children). Neither position accurately reflects reality, since any human being is to a certain extent both autonomous and dependent, contingent on the specific situation and context. ${ }^{32}$

\subsubsection{A case-based approach to human rights violations}

Another road towards an integrated perspective on rights holders has been suggested by Verdonck and Desmet, and consists in moving towards a 'case-based' approach in judicial proceedings. ${ }^{33}$ This would imply that the judicial actor concerned "would not assess the human rights violations caused to a certain person or group, but would assess the human rights violations caused by certain acts or omissions from a more holistic perspective, for a broader range of victims than only the petitioners who submitted the complaint under consideration.' ${ }^{34}$ A concrete procedural opening is found in the Inter-American human rights system to that end, based on the provision that allows the Inter-American Commission on Human Rights to initiate a petition on its own initiative (motu propio). ${ }^{35}$

30 David (n 10), 30-31.

31 See also introduction to section 1 and Brems (n 8) 452.

32 See also eg, Freddy Mortier, 'We zijn allemaal kinderen: bruggen tussen rechten voor kinderen en rechten voor volwassenen' (2002) Tijdschrift voor Jeugdrecht en Kinderrechten 10.

33 Lieselot Verdonck and Ellen Desmet, 'Moving Human Rights Jurisprudence to a Higher Gear: Rewriting the Case of the Kichwa Indigenous People of Sarayaku v Ecuador (Inter-Am. Ct HR)' in Eva Brems and Ellen Desmet (eds), Integrated Human Rights in Practice. Rewriting Human Rights Decisions (Cheltenham, Edward Elgar Publishing, 2017).

34 Ibid, 475.

35 Art 24 Rules of Procedure of the Inter-American Commission on Human Rights of 2009. 
The Inter-American Court of Human Rights has interpreted this provision as referring to the possibility not only of filing a 'new' petition, but also of including other victims in an existing application. ${ }^{36}$ By moving from a personal approach in judicial petitions (focusing on the applicants) to a more factual/case-based approach, all other persons affected by the issue would be included, and a maximum inclusion of rights holders obtained. Inspiration could be drawn from Truth and Reconciliation Commissions, which first focus on the events to be investigated and then on the identification of persons involved. Such a case-based approach would require a rather radical change of the human rights system, though, which calls for further exploration.

\section{METHODOLOGICAL SOPHISTICATION IN STUDYING USERS' PERSPECTIVES}

Adopting a users' perspective on human rights law implies a shift in analytical perspective. Rather than embarking on research from the entry point of a specific legal instrument, topic or monitoring mechanism, one puts oneself in the shoes of those individuals or entities who engage with human rights-the 'users' ${ }^{37}$ This users' perspective can be situated within a broader turn in human rights scholarship towards a more context-sensitive and actor-oriented approach. ${ }^{38}$ Conceptualized in $2014,{ }^{39}$ the users' perspective on human rights law has been developed and refined during the past years through its application in research projects. In this way, the hypothesis that a users' perspective can be usefully adopted not only in empirical research but also in desk studies, ${ }^{40}$ was confirmed. ${ }^{41}$ Other findings relate to the selection of human rights

36 Blake v Guatemala, Inter-American Court of Human Rights (ser C) No 36 (24 January 1998).

37 Ellen Desmet, 'Analysing Users' Trajectories in Human Rights: A Conceptual Exploration and Research Agenda' (2014) 8(2) HR\&ILD 121, 123-24.

38 Ibid, 122.

39 Brems and Desmet (n 7).

40 Desmet (n 37) 133.

41 For desk studies adopting a users' perspective on human rights, see eg, David (n 10); Marijke De Pauw, 'International Human Rights Law: Between Fragmentation and Coordination. A Case Study on the Emerging Rights of Older Persons' (PhD thesis, Vrije Universiteit Brussel and Université Saint-Louis Bruxelles 2017); the contribution of Holvoet and De Hert in this volume; Dorothea Staes, 'When the European Court of Human Rights refers to external 
users, their categorization, and the involvement of researchers with/as human rights users, and are discussed here below.

\subsection{Selecting Human Rights Users}

When selecting users for active participation in a research project, for instance, through interviews or focus groups, the question arises whether their familiarity with human rights will constitute a selection criterion. In case of random selection, research participants will include 'potential users', ie, persons who could use human rights but have not (yet) done so. ${ }^{42}$ A deliberative selection can limit the research to 'actual' users of human rights. Two projects illustrate these choices and their consequences. In their study of human rights cities in the Netherlands, Oomen and van den Berg chose to interview urban actors 'with an interest in using human rights'. ${ }^{43}$ This 'clear bias' in the selection of research participants - who were more acquainted with human rights than average persons-was justified by the project's aim of 'describing the experiences and perspectives of local users of human rights in order to weigh the advantages and pitfalls of a human rights framework' ${ }^{44}$ Oomen and van den Berg identified different ways in which human rights were used by urban actors: as a benchmark, as a mobilizing force, and as a demarcation of local autonomy. They concluded that urban actors can be characterized as 'idealistic pragmatic users' of human rights: they believe in human rights (idealistic) but use them strategically and selectively (pragmatic). ${ }^{45}$

By contrast, in a study of Chen, Desmet and De Feyter on the relevance of the right to education for rural-urban migrant children in Chongqing (China), parents and children were interviewed without prior knowledge of their level of human rights awareness and use. ${ }^{46}$ Although many people 'had heard of' rights-related notions, ${ }^{47}$ the actual use of

instruments. Mapping and justifications' (PhD thesis, Université libre de Bruxelles and Université Saint-Louis - Bruxelles 2017).

42 Desmet (n 37) 137.

43 Barbara Oomen and Esther van den Berg, 'Human Rights Cities: Urban Actors as Pragmatic Idealistic Human Rights Users' (2014) 8(2) HR\&ILD 160, 172.

44 Ibid.

45 Ibid, 183.

46 Jinrong Chen, Ellen Desmet and Koen De Feyter, The Right to Education of Rural-Urban Migrant Households in Chongqing, China (Localising Human Rights Working Paper Series no. 3) (University of Antwerp, 2016), 39.

47 Ibid, 110. 
human rights turned out to be very limited. Consequently, the research concentrated on identifying factors that could explain this virtual absence of human rights claims and actions. Contextual (political climate and cultural context), socio-economic (migration status, education and social networks) and socio-psychological (eg, internal or external attribution, perception of agency, group pressure) elements all played a role in explaining the limited recourse to human rights by these potential users. ${ }^{48}$ In settings where human rights are not predisposed to play a role, their influence is thus not to be overestimated. ${ }^{49}$ In the particular context of the study in Chongqing, the open selection of research participants as to their familiarity with human rights led to a reorientation of the research questions, from analysing the relevance of human rights to explaining why human rights were not used. Of course, in many other contexts, an at random selection of interviewees will probably lead to a mixed sample of actual and potential users of human rights.

\subsection{Categorizing Human Rights Users}

In 2014, four categories of human rights users were conceptually distinguished..$^{50}$ Rights claimants invoke human rights in order to change their own (potentially) unsatisfactory situation. Their claims may be supported by current human rights law or trigger new standard-setting or progressive interpretations. Rights realisers give effect to human rights, acting upon either a legal obligation or other (eg, moral or instrumental) considerations. Supportive users contribute to the realization of human rights. This category encompasses a wide variety of actors, such as NGOs, grassroots organizations, lawyers, national human rights institutions and the UN charter- and treaty-based bodies. Finally, judicial users, such as courts and tribunals, impose the implementation of human rights upon other actors. Whereas rights claimants and rights realisers can be considered direct users of human rights, supportive users and judicial users are grouped together as indirect users. These categories are empirical rather than legal. In practice, however, the empirical categories (eg, rights claimants and rights realisers) may to a certain extent overlap with legal categories (eg, rights holders and duty bearers respectively). It

\footnotetext{
48 Ibid, 94-110.

49 Ellen Desmet, 'Rural-Urban Migration And Education In China: Unraveling Responses To Injurious Experiences' in Tine Destrooper and Sally Engle Merry (eds), Human Rights Transformation in Practice (Philadelphia, University of Pennsylvania Press, 2018).

50 Desmet (n 37) 129-31.
} 
must be emphasized that the identification of human rights users should be done in concreto, taking the specific context into account: depending on the situation, an individual can be a rights claimant (eg, when invoking respect for her right to freedom of religion), a rights realiser (eg, when realizing the right to education of her children) and a supportive user (eg, when working for an NGO that defends the rights of asylum seekers).

These categories have been refined via their application in various research projects. Interestingly, as concerns the category of supportive users, the proposed adjustments go in opposite directions, pointing to the relevance of a context-sensitive approach. Looking at the role of human rights organizations and legal representatives in defending migrant rights in judicial proceedings, Ganty and Baumgärtel find that the term 'supportive users' does not do justice to the key role these actors play in augmenting the capabilities of migrants. These actors function rather as 'enabling users'.51 In their view, 'this enlarged role entails ... the existence of a moral duty, effectively transforming organizations and legal representatives into another category of "rights realiser". 52 By contrast, in order to refer to third parties that intervene in the proceedings before the ECtHR, Staes refrains from employing the term 'supportive users'. Speaking instead of 'third party users', she points to the fact that such actors do not always act in a way that supports the realization of human rights; they may also contest the application or evolutive interpretation of particular human rights. This may especially be the case in a context of conflicting rights, where third party interveners may support the extensive protection of one right (eg, freedom of expression) to the detriment of another right (eg, freedom of religion). ${ }^{53}$

\subsection{Engaging With and Becoming More Active Human Rights Users}

In various of the empirical studies undertaken, the researchers actively engaged with the users of human rights that they were doing research on. In this way, the researchers became more actively supportive users of

51 Sarah Ganty and Moritz Baumgärtel, 'Effective Remedies as Capabilities: Towards a User Perspective on the Human Rights of Migrants in Belgium' (2014) 8(2) HR\&ILD 215, 232.

52 Ibid.

53 Staes (n 41), nos 114-15. 
human rights. ${ }^{54}$ This has been the case in research on a variety of topics in a diversity of places, including human rights cities in the Netherlands, the rights of trans people in Belgium, and the right to water and sanitation for the urban poor in New Delhi, India. In the first two cases, the involvement of the researchers was anticipated in the research design, in the latter it was triggered by the unexpected partial demolition of a slum.

When researching Dutch human rights cities, Oomen and van den Berg were actively involved in raising awareness on the relevance of human rights for local urban actors. This means that they participated in interviews or meetings by providing information and sharing knowledge. To counterbalance this involvement, the authors note: 'At the same time, we safeguarded our independent role as researchers and are committed to autonomous reporting and also to noting ... the pitfalls for framing concerns as human rights issues at the local level'. ${ }^{55}$

In their contribution to this volume, Bribosia and Rorive relate how they cooperated with trans people and their representative organizations, in order to change Belgian legislation on gender recognition procedures. ${ }^{56}$ Their clinical legal education project led them to being part of the social struggle, in order to grasp the diversity among trans people and get a thorough understanding of their claims. Their account is also illustrative of the need for flexibility in this kind of action research, as political momentum steered their efforts away from strategic litigation to the drafting of a model law.

Finally, in a case study on the right to water and sanitation for urban slum dwellers in New Delhi, carried out under the supervision of De Feyter, the research team was confronted with a crisis situation resulting from the destruction of parts of a site, and the arrest and detention of three women. ${ }^{57}$ Feeling ethically obliged to help the people they had been doing research on, the researchers temporarily changed their role 'from observers to actors', and assisted in, for instance, alerting the media and writing a letter to the UN Special Rapporteur on the right to housing on the matter. It is left to the reader to assess a possible interference of these actions with the research aim of studying the

54 Researchers as such could also - depending on their stance - qualify as supportive users of human rights, yet in a more passive way.

55 Oomen and van den Berg (n 43), 172.

56 See the contribution of Bribosia and Rorive in this volume.

57 Koen De Feyter and others, The Right to Water and Sanitation for the Urban Poor in Delhi (Localising Human Rights Working Paper Series no 4) (University of Antwerp, 2016), 186-92. 
importance of connections with NGOs and UN actors for local people using human rights.

In a world where human rights are increasingly under pressure, these cases illustrate the encounter between human rights research and human rights action, where transparent reporting becomes even more important.

\section{EMERGING SHARED CHARACTERISTICS}

Looking back at the various research projects carried out with the overall objective 'to study human rights law as an integrated whole from a users' perspective', three methodological characteristics emerge as particularly prevailing: (i) 'cross-thinking', understood as thinking across boundaries within human rights law as well as across disciplines; (ii) a focus on impact and effectiveness; and (iii) collaborative research. The identification of these three characteristics does not imply that every research project on human rights integration and/or users' perspectives will necessarily display these three characteristics. Nevertheless, there seems to be a positive correlation between research tackling the aforementioned research objective and the three methodological features elaborated upon hereinafter.

\subsection{Cross-thinking}

Studying human rights law as an integrated whole from a users' perspective often seems to go hand in hand with thinking beyond established boundaries and typologies. Approaching human rights law in an integrated manner and/or putting oneself in the shoes of human rights users frequently requires human rights scholars to step outside of their niche of expertise, and look afresh at the broader field of human rights law. This methodological characteristic can be labelled as 'crossthinking', with a term borrowed from Valeska David yet given a broader meaning here. ${ }^{58}$

Studying human rights law as an integrated whole from a users' perspective activates cross-thinking at two levels. First, it implies thinking across boundaries within human rights law, scholarship and practice. For instance, David brings together claims situated on two axes of difference, which are usually approached separately in jurisprudence and scholarship: claims of cultural difference and of economic difference. She shows the exclusionary effects of interpreting and constructing claims as related to

58 David (n 10) 26-27. See also section 1.1.1. 
only one of these axes. ${ }^{59}$ A key factor in the success of the Equality Law Clinic's work on the fundamental rights of trans people similarly implied thinking outside-the-box, building legal strategies on a variety of legally binding and non-binding provisions, from a human rights integration perspective. ${ }^{60}$ A final illustration is the research of Staes on crossreferencing, which explores when, how and why the European Court of Human Rights in its judgments refers to instruments other than the European Convention on Human Rights and its Protocols. ${ }^{61}$

Second, researching human rights integration from a users' perspective is often characterized by thinking across disciplines. Oomen has shown how insights from legal pluralism can contribute to a better understanding of the dynamics of human rights integration. ${ }^{62}$ For instance, the key concept within legal pluralism of 'semi-autonomous social field'referring to a social field that can generate rules and induce their compliance ('autonomous') yet is simultaneously influenced by norms and decisions coming from outside ('semi') ${ }^{63}$ — can be usefully applied to the multi-layered framework of human rights law. Each layer can be considered as a semi-autonomous social field, as it is constituted by, but also constitutive of, human rights law more broadly. ${ }^{64}$ Other characteristics of socio-legal theories of legal pluralism, namely the focus on actors, framing, ${ }^{65}$ power discrepancies and empirical research, can also help to better grasp human rights integration. For instance, actors may refer to diverse bodies of human rights law to strengthen their case, and in this

59 David (n 10).

60 See the contribution of Bribosia and Rorive in this volume.

61 Staes (n 41).

62 Barbara Oomen, 'The Application of Socio-Legal Theories of Legal Pluralism to Understanding the Implementation and Integration of Human Rights Law' (2014) 4 EJHR 471. For the application of a legal pluralist perspective on the fragmentation of international human rights law, namely as regards the rights of older persons, see De Pauw (n 41), 28-35.

63 Sally Falk Moore, 'Law and Social Change: The Semi-Autonomous Social Field as an Appropriate Subject of Study' (1973) 7 L \& Soc'y Rev 719, 720.

64 Oomen (n 62), 493.

65 The concept of framing helps to understand how an injustice comes to be perceived as a human rights violation in a particular setting, on the one hand, and how human rights are disseminated and appropriated, on the other. Ibid, 490. Oomen refers to Merry's definition of frames as 'packaging and presenting ideas that generate shared beliefs, motivate collective action and define appropriate strategies of action'. See Sally Engle Merry, 'Transnational Human Rights and Local Activism: Mapping the Middle' (2006) 108(1) Am Anthropol 38, 41. 
way contribute to human rights integration in a given social field. ${ }^{66}$ To develop her integrated, relational and inclusive approach to norms and rights holders in case law analysis, David has drawn on methods of feminism (such as intersectionality and relationality), literature and law, and critical legal theory. ${ }^{67}$

This interdisciplinary vocation when studying human rights integration and/or users' perspectives is also evident from the other contributions in this volume. For instance, Oomen further develops a grounded theory on the interrelated processes of fragmentation and integration of human rights law from a users' perspective. ${ }^{68}$ This, she argues, cannot be done without combining insights from different social science disciplines, such as political science (on state compliance with human rights law), sociology (on the social and historical contingency of rights) and anthropology (on the localization of human rights). Similarly, when working on transgender issues from a users' perspective, Bribosia and Rorive combined legal expertise with insights from medicines, sociology, anthropology, psychology and gender studies. In combination with regular meetings with trans organizations and people, this allowed them to get a full insight into the diversity among trans people and their claims, and to adequately translate social issues of trans people into legal demands. ${ }^{69}$ Carrying out research on the relevance of human rights for marginalized groups in the Global South ('localizing human rights') requires combining insights from law, social and political sciences. ${ }^{70}$ Focusing on indigenous peoples as users of human rights law, Inman, Smis and Dorneles de Andrade adopted a 'law and literature' approach to explore to what extent indigenous conceptions of land, territorial and resource rights are aligned with how international human rights law currently protects their lands, territories and natural resources. ${ }^{71}$ Finally, to explore the added value of one particular layer of human rights, namely constitutional bills of rights, Van Drooghenbroeck and Van der

\footnotetext{
66 Oomen (n 62), 494.

67 David (n 10). See sections 1.1.1 and 1.2.1.

68 See the contribution of Oomen in this volume.

69 See the contribution of Bribosia and Rorive in this volume.

70 See the Localising Human Rights Working Paper Series, available at https://www.uantwerpen.be/en/rg/law-and-development/publications/localisinghuman-rights/.

71 See the contribution of Inman, Smis and Dorneles de Andrade in this volume.
} 
Noot draw upon insights from law, sociology, legal philosophy and political philosophy. ${ }^{72}$

In sum, studying human rights law as an integrated whole from a users' perspective engenders the crossing of both 'internal' (within human rights law and scholarship) and 'external' (with other disciplines) boundaries, in order to better grasp the complex realities underlying human rights claims.

\subsection{Focus on Impact and Effectiveness}

Adopting an integrated approach to human rights is needed for full human rights justice' ${ }^{73}$ Looking from the perspective of human rights users in general, and rights claimants in particular, the lack of effectiveness of human rights law becomes particularly striking..$^{74}$ This focus on the impact and effectiveness of human rights protection has been concretized and operationalized in different ways.

Valeska David uses three analytical tools that support a concern with the effectiveness of human rights protection. First, drawing on feminism, she engages in 'practical reasoning', understood as reasoning that 'focuses close attention on the actual interests that are at stake in a case and to the effects of laws and practices over formal and a priori judgment' ${ }^{75}$ Second, based on a literary approach to law, she argues that a focus on effects is also inherent in a narrative or discursive approach to law, given that discourses 'do not only represent things. They also perform social functions. ${ }^{76}$ Third, again drawing on law and literature, she points to the capacity of law of 'empathetic thinking', whereby such an empathetic position enables a focus on the effectiveness of human rights law. ${ }^{77}$

Baumgärtel has developed an 'issue-based approach' to analyse the effectiveness of international court judgments. This approach allows 'the experiential evaluation of actual and practical impacts of international

72 Olivier Van der Noot, 'Debate on the Modernization of the Constitutional Bill of Rights in Europe. General overview' (2016) 77(2) Revue interdisciplinaire d'études juridiques 139. See also the contribution of Van Drooghenbroeck and Van der Noot in this volume.

\footnotetext{
73 Brems (n 8) 454.

74 Desmet (n 37) 125.

75 David (n 10) 28.

76 Ibid, 29.

77 Ibid, 30.
} 
judgments on a political issue of salience'. ${ }^{78} \mathrm{He}$ constructs 'issue-based effectiveness' of international court judgments as consisting of three interconnected dimensions: (i) law development effectiveness (contribution of the judgment to the development of law and doctrine); (ii) case-specific effectiveness (impact of the judgment on the parties in the case, namely the claimants and the defendant state $)^{79}$ and, most importantly; (iii) strategic effectiveness (impact of the judgment on 'the issue constituency', ie, the range of actors (often a transnational network) mobilizing around a particular 'issue'). ${ }^{80}$ The benchmark of evaluation is thus based neither on the legal mandates of international courts nor on the priorities of states, but on how the issue constituency perceives the contribution of the decision to resolving a specific issue. ${ }^{81}$ The issuebased approach allows judges who want to adopt a teleological interpretation of the treaty to situate the case at hand in a wider political context. $^{82}$ The approach could also offer the basis for a critical evaluation of the emancipatory potential of international courts as regards specific issues for groups that have experienced marginalization. ${ }^{83}$

Baumgärtel applies this framework to the issue of the human rights of vulnerable migrants, but argues that the framework has potential to be applied to other issues, and possibly also to international bodies other than courts. ${ }^{84}$ Yet, he identifies two methodological limitations to be addressed by future research. A first question concerns assessing the impact of structural problems on the court's functioning. This challenge is not particular to the issue-based approach, however, but a general one faced by all research on international courts. A second question that remains open is the one of efficiency and opportunity costs. Baumgärtel has found that international court judgments have only a limited impact on the realization of migrant rights, yet are very 'expensive' as far as

78 Moritz Baumgärtel, 'From Deficit to Dilemma. An Evaluation of the Contribution of Europe's Supranational Courts to the Promotion of the Rights of Vulnerable Migrants' (PhD thesis, Université libre de Bruxelles 2016) 12.

79 Ibid, 7-8. Baumgärtel indicates that these first two dimensions are taken from Laurence Helfer. Laurence R Helfer, 'The Effectiveness of International Adjudicators' in Cesare PR Romano, Karen J Alter, and Chrisanthi Avgerou, The Oxford Handbook of International Adjudication (Oxford, Oxford University Press, 2013) 464-65.

80 Ibid.

81 Ibid, 29-33 and 41.

82 Ibid, 35.

83 Ibid, 37. The issue selected could also be one of interest to more powerful actors, such as states or companies, though. Ibid, 38 .

84 Ibid. 
human and financial resources are concerned. This begs the question whether litigation is 'really worth it', or whether migrant rights would be better served by investing scarce resources in for instance lobbying and awareness raising. ${ }^{85}$

Research on human rights law and jurisprudence often focuses on legal constructions and argumentations, without paying equal attention to whether and how laws and judgments actually contribute to realizing a life in dignity for all. An integrated approach to human rights law from a users' perspective contributes to the timely shift toward studying the impact and effectiveness of human rights law.

\subsection{Collaborative Research}

Within law faculties, it is still somewhat unconventional to engage in long-term and intensive teamwork. ${ }^{86}$ Collaborations are mostly limited to the work relationship between a $\mathrm{PhD}$ student and her supervisor and the - often one-off - co-authoring of a piece. Nevertheless, various of the methodologies proposed in this chapter only come to their full potential when collaboratively engaged with. This is particularly the case for the methodology of analysing interactions between different branches of human rights law, which is prone to result in more interesting findings when experts of various legal sub-disciplines join forces. It is equally beneficial to engage in a rewriting exercise from different backgrounds and (sub-)disciplinary perspectives. Edited volumes and special issues are then well-suited publication channels for this type of research effort, which ideally take off and/or land with a thorough discussion of each contribution at a seminar or conference.

Conducting research on the use of human rights in other cultural contexts may be much facilitated through collaborating with local researchers. As such, case studies on the use of human rights by local groups in China, the DRC and India were conducted by international, intercultural and multidisciplinary research teams, under the supervision of De Feyter. ${ }^{87}$ The partner institutions in the Global South were selected

85 Ibid, 36-7.

86 See also Claire Massey and others, 'Crossing Fields: The Case of a Multi-disciplinary Research Team' (2006) 6 Qualitative Research 131, 131.

87 On localising human rights research, see generally Koen De Feyter, 'Localising Human Rights' in Wolfgang Benedek, Koen De Feyter and Fabrizio Marrella (eds), Economic Globalisation and Human Rights (Cambridge, Cambridge University Press, 2007); Koen De Feyter, 'Sites of Rights Resistance' in Koen De Feyter and others (eds), The Local Relevance of Human Rights 
on the basis of prior contacts or collaborations, which had the benefit of building on existing trust relationships. The local partner also proved essential to ensure that the research was contextually sensitive, as regards both the selection of the research topics and the actual implementation of the research. Moreover, collaborating with partners in the Global South contributes to building their (socio-legal) research capacity. This is a more long-term benefit that contributes to correcting the imbalance in financial and human resources between universities in different parts of the world. Notwithstanding efforts to work as inclusively as possible and to arrive at horizontal working relationships, the fact that funding-and thus ultimate decision-making power on resource allocation-rested with one side, inevitably upheld a certain power relationship.

Doing research in such intercultural and multidisciplinary research teams is a both challenging and enriching experience. Such research is time-consuming, as people need to get to know each other, both professionally and personally. They need to familiarize themselves with other frames of reference and different ways of communicating, and try to arrive at a shared conceptual and methodological framework. A benefit of intercultural research teams is that insider and outsider perspectives can be combined, for instance in the phases of research design and data analysis. Such a 'thick' understanding of reality requires much dialogue and exchange, but leads to a more in-depth and nuanced analysis. The phase of data collection was mainly taken up by the local research team. ${ }^{88}$ This had the advantage of, among others, speaking the local language, being aware of cultural and political sensitivities, and being able to appropriately assess security risks.

In conclusion, studying human rights law as an integrated whole from a users' perspective seems conducive to collaborative research, which in its turn increases the probability of innovative, robust and grounded research findings.

(Cambridge, Cambridge University Press, 2011); and Koen De Feyter, 'On the Local Relevance of Human Rights' in Anthony Tirado Chase (ed), Routledge Handbook on Human Rights and the Middle East and North Africa (Abingdon, Routledge, 2017). This part of the section is based on my involvement as a methodological coordinator (to a different degree for each case study) and on conversations with team members.

88 With the exception of part of the DRC project and a few field visits in the other projects by Belgian team members. 


\section{RELEVANCE BEYOND HUMAN RIGHTS LAW}

Both the integrated approach to human rights law and the users' perspective hold potential beyond human rights law. To start, a comprehensive approach to norms - the first dimension of an integrated approach - could be adopted to study the relation between human rights law and other fields of law. The interactions methodology seems particularly suitable here. Even though many studies have explored the role of human rights within other fields of law, ${ }^{89}$ they seem to adopt a unidirectional perspective, only considering the impact of human rights on the other field. This chapter submits that the systemic and systematic approach of the interactions methodology would lead to an enhanced sensitivity to, on the one hand, conceptual and structural particularities of each field of law and, on the other, existing and possible future interaction between human rights law and other fields of law.

Second, an integrated approach to human rights norms could usefully be adopted by other fields of law in themselves, without considering their relation with human rights law. Multi-layeredness and fragmentation are not exclusive characteristics of human rights law. Given the multiplication of legal norms at different levels, in different fora, on different issues and with different legal force in many fields of law other than human rights law, these fields could benefit as well from a 'smart integrated approach' - combining the benefits of integration and fragmentation. ${ }^{90}$ As an illustration, the relevance of an integrated approach to environmental law is hereinafter succinctly argued. Drawing on the approach of Brems in her analysis of the multilayered nature of human rights law, ${ }^{91}$ environmental law instruments can be found at different

89 For some examples, see, on international criminal law: Krit Zeegers, International Criminal Tribunals and Human Rights Law: Adherence and Contextualization (The Hague, Asser Press and Springer, 2016); on international investment law: Pierre-Marie Dupuy, Francesco Francioni and Ernst-Ulrich Petersmann, Human Rights in International Investment Law and Arbitration (Oxford, Oxford University Press, 2009); on private international law: JJ Fawcett, Máire Ní Shúilleabháin and Sangeeta Shah, Human Rights and Private International Law (Oxford, Oxford University Press, 2016). A more systemic approach seems to be adopted in Roberta Arnold and Noëlle NR Quénivet, International Humanitarian Law and Human Rights Law: Towards a New Merger in International Law (Leiden, Martinus Nijhoff Publishers, 2008).

90 See the contribution of Brems in this volume.

91 Brems (n 8) 448-51. 
governance levels, including the (sub)national, the regional ${ }^{92}$ and the international. ${ }^{93}$ They can be differentiated on the basis of their scope ratione materiae, regulating different (but connected) issues such as biodiversity, ${ }^{94}$ climate change, ${ }^{95}$ the protection of the ozone layer, ${ }^{96}$ and hazardous substances and waste. ${ }^{97}$ Environmental texts can also be distinguished as regards their legal force, including treaties but also an important number of soft law instruments. ${ }^{98}$ The two elements that are more difficult to apply are scope ratione personae and monitoring mechanisms. ${ }^{99}$ Overall, however, it could similarly be hypothesized that a compartmentalized approach to environmental law will lead to a suboptimal protection of the environment. Whereas in human rights law, arguments of intersectionality support an integrated approach, in environmental law, an integrated approach would be spurred by the inextricable links between environmental challenges such as climate change, biodiversity conservation and desertification.

92 For example, the United Nations Economic Commission for Europe (UNECE) Convention on Access to Information, Public Participation in Decision-Making and Access to Justice in Environmental Matters 1998 (Aarhus Convention); the Regional Seas Programme of UNEP (a legal framework for protecting seas at the regional level).

93 For example, UN Framework Convention on Climate Change and Kyoto Protocol; UN Convention on Biological Diversity.

94 UN Convention on Biological Diversity.

95 UN Framework Convention on Climate Change and Kyoto Protocol.

96 Convention for the Protection of the Ozone Layer, Vienna, 1985; Montreal Protocol on Substances that Deplete the Ozone Layer, 1987.

97 Convention on the Control of Transboundary Movements of Hazardous Wastes and their Disposal, Basel, 1989; Rotterdam Convention on the Prior Informed Consent Procedure for Certain Hazardous Chemicals and Pesticides in International Trade, 1998; Stockholm Convention on Persistent Organic Pollutants, 2001.

98 Stockholm Declaration on the Human Environment, 1972; UNEP Draft Principles of Conduct in the Field of the Environment for the Guidance of States in the Conservation and Harmonious Utilization of Natural Resources Shared by Two or More States, 1978.

99 Whereas in human rights law, human beings are the obvious rights holders, identifying rights holders in environmental law is less clear-cut (even though some jurisdictions have recently recognized for instance rivers as rights holders). In addition, the range of monitoring mechanisms in environmental law is less diverse and less coercive compared to human rights law. There are, for instance, no regional or international environmental law bodies with the capacity to adopt (quasi-)judicial decisions. 
Moreover, also the users' perspective can be fruitfully applied beyond human rights law, as demonstrated by the adoption of a users' perspective to international criminal law by Holvoet and De Hert in this volume. ${ }^{100}$ They distinguish between seven user groups: victims as rights claimants of international criminal law; NGOs as legal service providers; the accused as a vulnerable user (with a question mark); states; prosecutors; judges, human rights bodies or courts and commissions of inquiry; and academics and the International Law Commission. Tailoring the users' perspective to the specificities of international criminal law leads to the identification of different groups of users. Different from the functional and empirical approach proposed in the categorization of human rights users (where the categorization of a certain user will depend on how this user engages with human rights in a particular context: an NGO may be a rights claimant, a supportive user and/or a rights realiser, depending on the particular circumstances), the user groups distinguished in international criminal law do not vary with the function, but rather with the position of the user in the international criminal law field. It is not clear whether international criminal law is considered to be 'used' in the same way (invoked, realized, supported and imposed) as this was suggested in relation to international human rights law.

A users' perspective could also be usefully adopted beyond human rights law. Belgian migration law, for instance, is divided into various and complex procedures, which vary with the decisive element invoked to claim residence rights (asylum, family reunification, labour migration, medical regularization etc). When a procedure based on one element of a migrant's situation (eg, the risk of being persecuted) ends with a (final) negative decision, another procedure is often started (eg, medical regularization). Even though not explicitly adopting the language of 'users' perspective', Vanheule has argued that this compartmentalization of procedures has as a consequence that the situation of the migrant is never considered in a holistic way. Implicitly adopting the perspective of the migrant as the main 'user' of migration proceedings, he pleads for 'a unique residence decision', which would consider all claims to residence rights together. ${ }^{101}$ Adopting a users' perspective could thus lead to suggestions for legal reform and procedural optimization.

\footnotetext{
100 See the contribution of Holvoet and De Hert in this volume.

101 Dirk Vanheule, 'Alternatieven in de rechterlijke geschiloplossing in asiel en migratie' (Academische Zitting 10 jaar Raad voor Vreemdelingenbetwistingen, Brussels, 18 May 2017).
} 


\section{CONCLUDING REFLECTIONS}

This chapter discussed methodological approaches developed in order to study human rights law integration and fragmentation from a users' perspective. Significant progress has been made in developing methodological approaches to study human rights norms in an integrated way. Three methodologies were explained and compared, namely relational and inclusive case law analysis, rewriting judicial and quasi-judicial decisions from an integrated perspective on human rights norms, and analysing interactions between different branches of human rights law and general human rights law. Depending on the particular research objective, some methodologies will be more suited than others. In comparison, the development of methodologies to arrive at an inclusive approach to rights holders has received less research attention until now. Seeds have been sown, however, in the forms of relational and inclusive case law analysis and the suggestion to move toward a case-based approach to human rights violations. Future research could develop more methodological tools to approach affected rights holders in an inclusive way.

Thereinafter, the focus of the chapter shifted to methodological refinements made in the study of users' perspectives. After some reflections on the at random or deliberative selection of research participants, it was demonstrated how various research projects led to diverging suggestions to fine-tune the category of 'supportive' users. Moreover, researching the use of human rights illustrates the thin line between human rights research and human rights action. A next step in doing research from a users' perspective could be to engage in co-construction of knowledge with the users concerned.

Three common features of studying human rights law as an integrated whole from a users' perspective were discussed: cross-thinking (understood as thinking across established boundaries both within human rights law and between disciplines), a focus on impact and effectiveness, and a tendency to engage in collaborative research. The chapter closed with illustrating the relevance of adopting an integrated approach and/or a users' perspective beyond the field of human rights law, for instance in international criminal law and migration law. The potential of applying the perspectives of integration and users to other fields of law seems far from fully tapped.

During the past years, the research objective of 'studying human rights law as an integrated whole from a users' perspective' has led to the development of various innovative methodologies, each with their own 
particularities, benefits and drawbacks. It is hoped that the application of these methodologies in other research projects, fields and disciplines will contribute to their further sophistication and robustness. 